\title{
Massive hemothorax in a pregnant patient with neurofibromatosis type 1
}

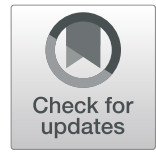

Kumiko Hashimoto $^{1 *}$, Yuji Nomata ${ }^{1}$, Takayuki Fukui ${ }^{2}$, Akira Takada $^{3}$ and Kunio Narita ${ }^{1}$

\begin{abstract}
Background: Reports of spontaneous hemothorax in patients with neurofibromatosis type 1 are scarce despite the severe complication. We herein present the first case of hemothorax in a neurofibromatosis type 1 patient during pregnancy and discuss the difficulty associated with its diagnosis and treatment.

Case presentation: A 39-year-old female at 34 weeks gestation presented with sudden left back pain and dyspnea. Chest radiography revealed massive left pleural effusion. Computed tomography showed bleeding from the intercostal artery. Although the patient appeared hemodynamically stable, the fetus was in a critical condition. Emergency caesarean section was performed within 1 hour. Subsequently, we performed endovascular coil embolization of the intercostal artery. While this intensive treatment saved the patient, her fetus could not be rescued.
\end{abstract}

Conclusions: Patients with neurofibromatosis type 1 may develop massive hemothorax without gross lesions. In late pregnancy, sufficient infusion and quick hemostasis are essential and can be lifesaving.

Keywords: Hemothorax, Pregnancy, Emergency

\section{Background}

Spontaneous hemothorax is rare, and case reports on this condition are scarce [1]. Physiological changes in the perinatal period are thought to be one of precipitation factors for hemothorax in patients with pulmonary arteriovenous malformation and hereditary telangiectasia [2]. However, there have been only three reports of spontaneous hemothorax in patients with neurofibromatosis type 1 (NF1), all of which occurred in the postpartum period. Herein, we present the first case of hemothorax during pregnancy in a patient with NF1.

\section{Case report}

A 39-year-old female at 34 weeks gestation presented with sudden left back pain and dyspnea. She had been diagnosed with NF1 over 20 years prior. She had no

\footnotetext{
* Correspondence: 935hashimoto@gmail.com

'Department of Thoracic Surgery, Toyohashi Municipal Hospital, 50

Hachiken-nishi, Aotake-cho, Toyohashi, Aichi 441-8570, Japan

Full list of author information is available at the end of the article
}

family history of NF1 and no history of chest trauma, prior surgery, or catheter insertion. She was being treated for gestational hypertension.

On arrival, she was conscious with a blood pressure of $110 / 90 \mathrm{mmHg}$ and pulse rate of 90 beats $/ \mathrm{min}$. Her hemoglobin level was $10 \mathrm{~g} / \mathrm{dL}$ and oxygen saturation was $97 \%$ with $10 \mathrm{~L} / \mathrm{min}$ oxygen delivered via mask. Chest radiography revealed a massive left pleural effusion with left-to-right mediastinal shift (Fig. 1). Chest computed tomography $(\mathrm{CT})$ revealed a left pleural effusion and irregularities of the left 10th intercostal artery (Fig. 2). We suspected hemothorax because the CT value of the effusion was 45 Hounsfield units. Furthermore, CT findings also implied intrathoracic dural ectasia close to the artery. A chest tube was inserted immediately; however, only $400 \mathrm{~mL}$ of old blood could be removed, and no further significant discharge was collected though the pleural effusion remained. The patient was hemodynamically stable following fluid resuscitation; however, the fetal heart rate was decreasing, and the 


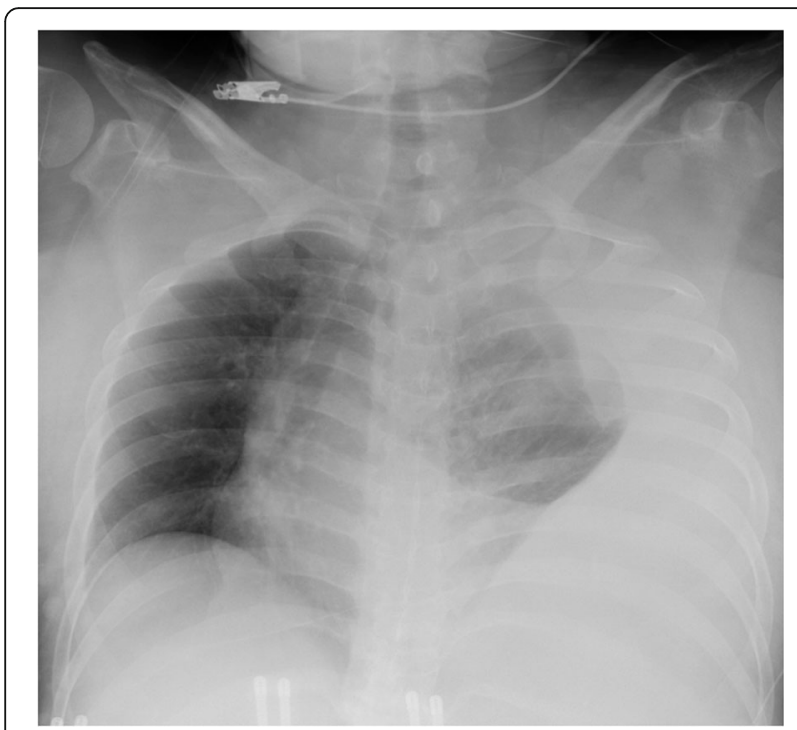

Fig. 1 Frontal chest radiograph showing massive left pleural fluid collection with a mediastinal shift to the right

fetus was in a critical condition. After obstetric consultation, we performed an immediate caesarean section under general anesthesia; the operative time was $40 \mathrm{~min}$ and the volume of blood lost including amniotic fluid was $300 \mathrm{~mL}$.

Selective angiography revealed irregular vessels and small aneurysms of the left 10th intercostal artery (Fig. 3a). Extravasation of contrast agent could not be detected. Therefore, we embolized the irregularly shaped portion of the artery. The distal site was embolized using 20 micro coils: 6 Orbit Galaxy (Codman \& Shurtleff, Raynham, MA), 6 Tornado Embolization Coils (Cook

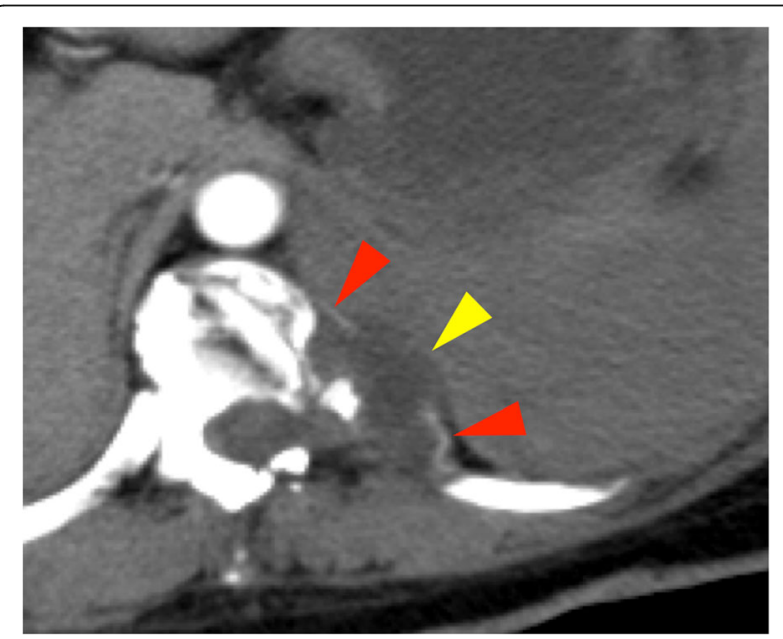

Fig. 2 Chest computed tomography showed a massive hemothorax and an irregularly shaped left 10th intercostal artery (red arrow). Intrathoracic dural ectasia was observed close to the artery (yellow arrow)
Medical, Bloomington, IN), 6 Azur Embolization System CX18 (MicroVention Inc., Aliso Viejo, CA), and 2 Interlocking Detachable Coils (Boston Scientific Corporation, Marlborough, MA). The proximal site was occluded using 3 Orbit Galaxy Microcoils. The artery and aneurysms were all embolized successfully (Fig. 3b). The duration from hospitalization to completion of treatment was about $5 \mathrm{~h}$.

The patient's condition improved postoperatively. Her blood pressure after caesarean section was 90/60 $\mathrm{mmHg}$. After embolization, it increased to $160 / 80 \mathrm{mmHg}$. Although the intensive treatment saved her life, the fetus could not be saved. Twenty days after embolization, lest pleural cavity decortication was performed and about $2500 \mathrm{~g}$ of hematoma was removed; the constriction of the left lung was released. One month post embolization, the patient was discharged in good condition. No further aneurysms or irregular arteries were found on full-body contrast-enhanced CT before discharge. No symptoms of recurrence ware reported during the next 18 months, and we followed up with CT regularly.

\section{Discussion and conclusions}

The autosomal dominant genetic disease NF1 affects approximately 1 in 3000 births [3]. Patients often suffer from malignant neoplasms and various other comorbidities [4-6], thus requiring continuous medical support. Vasculopathy is less common though severe complication with an incidence of only $3.6 \%$ [7]. The occurrence of hemothorax in the perinatal period has been reported in only three cases of NF1, all postpartum $[5,6]$. To the best of our knowledge, this is the first case of massive hemothorax in a pregnant patient with NF1.

In small arteries such as the intercostal artery, invasion by neurofibroma causes intimal thinning of the media, elastic fragmentation, and aneurysmal dilatation, which are influenced by the fragile nature of the vascular tissue [8]. Vascular lesions of small arteries are often asymptomatic and may thus go undetected before severe complications occur.

Hemothorax develops when other factors, such as tumors and aneurysms, overlap with vascular vulnerability [4]. Furthermore, pregnancy might be considered a precipitating factor for hemothorax in patients with NF1. Pregnancy exacerbates NF1 itself $[5,6]$; furthermore, increased intrathoracic pressure, blood volume, and cardiac output lead to increased blood pressure. Elevated steroid hormone levels also increase vascular fragility.

Hemorrhagic shock may be overlooked in late pregnancy. Blood volume in late pregnancy is $40-50 \%$ higher and the blood pressure may drop after $40 \%$ of circulating blood volume (1.5 L) is lost [9]. The fetus is directly affected by this decreased blood flow. In our case, the patient seemed hemodynamically stable despite persistent 


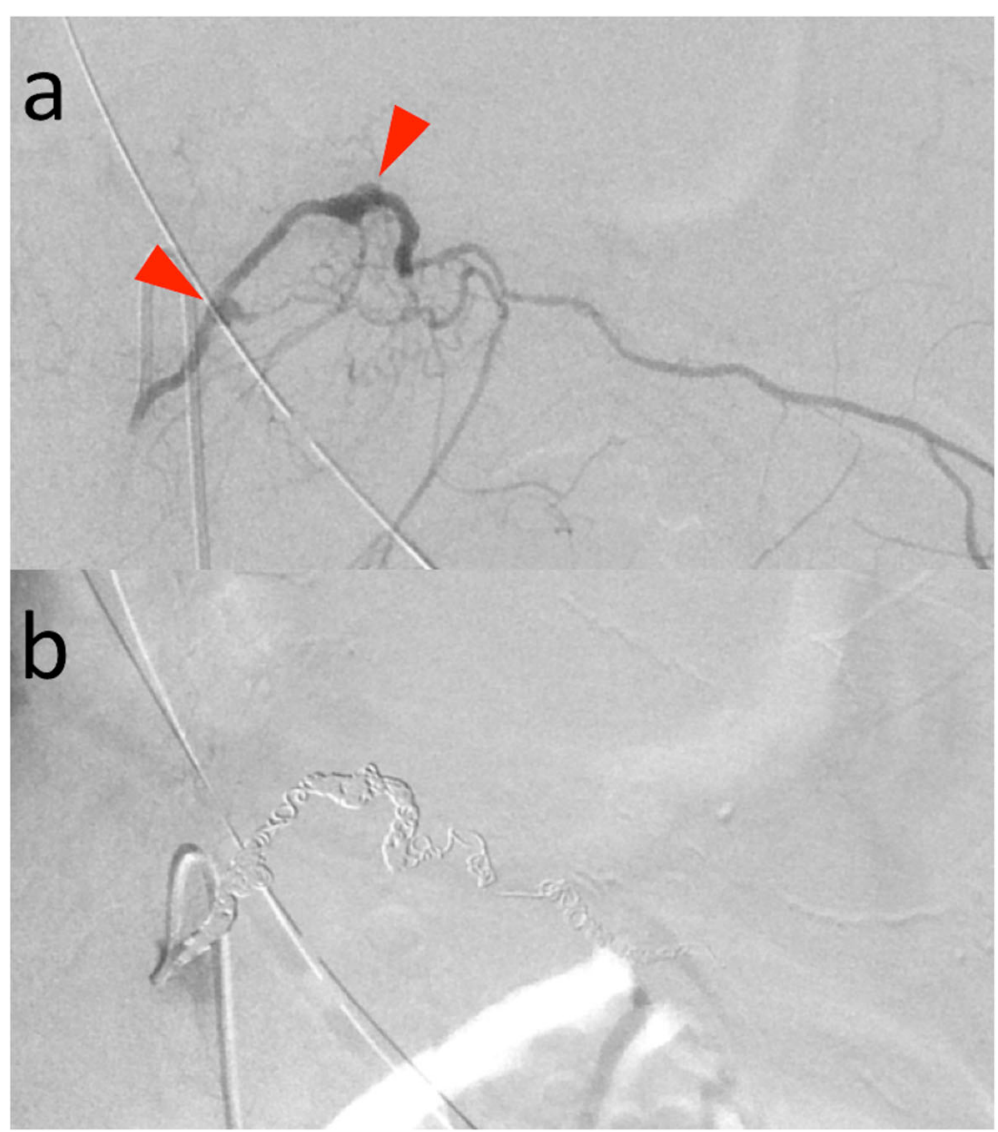

Fig. 3 a Selective left 10th intercostal arteriography demonstrated irregular vessels and small aneurysms (red arrows). Extravasation of contrast agent was not detected. $\mathbf{b}$ Left 10th intercostal arteriography after coil embolization showed complete occlusion of the aneurysms

bleeding. Therefore, we focused on the fetus and performed emergency caesarean section within 1 hour from admission, which was a very high risk procedure for the patient.

Rapid infusion in the emergency room usually targets a blood pressure of $100 \mathrm{mmHg}$. However, this infusion was insufficient in our patient to maintain fetal circulation. More infusion may have improved the fetal condition and caesarean section could have been avoided. Embolization should be performed immediately with adequate infusion. In our patient, the time to embolization was only $90 \mathrm{~min}$. Her blood pressure improved to 160 $\mathrm{mmHg}$ after embolization, indicating the severity of bleeding. Complete bleeding could be halted after $5 \mathrm{~h}$ from the time of arrival and there is a dire need to significantly cut down this timing to achieve better outcomes.

For hemorrhagic shock associated with obstetrical bleeding, transport to the operating room and emergency caesarean section should be a priority. However, since our patient presented with hemorrhagic shock from an unknown cause, scrutiny and discussion with obstetrician were necessary. We believe that the fetus could have been rescued if the patient was operated soon after presenting to the hospital. However, embolization delayed more without scrutiny in emergency room.

Several treatments have been reported for hemothorax, including conservative treatment with drainage, thoracotomy, and endovascular coil embolization [3]. In this case, the bleeding site was detected on contrastenhanced CT; therefore, endovascular treatment was feasible. Surgical repair would not have been safe as the field of view would have been obscured by the massive hematoma and dural ectasia. Furthermore, the proximity of the site of bleeding to the dural ectasia implied a risk of perforation during the procedure. In cases there the site of bleeding extends further to the proximal side, intrathoracic surgical repair is no feasible. Therefore, considering the fragility of the artery, the site of bleeding, and the presence of dural ectasia, surgical repair would have been extremely risky.

This case study demonstrates that, even in cases without gross lesions such as tumors and aneurysms, patients with NF1 have the potential to develop massive hemothorax during the perinatal period. Since it is 
difficult to prevent this outcome, strict hospitalization or blood pressure control, especially late in pregnancy and postpartum, should be considered in these patients. When massive hemothorax does occur, immediate endovascular treatment with adequate infusion should be preferred.

\section{Abbreviations}

CT: Computed tomography; NF1: Neurofibromatosis type 1

\section{Acknowledgments}

None.

\section{Authors' contributions}

All authors read and approved the final manuscript. $\mathrm{KH}$ performed the treatment decision and wrote this report. NY contributed to patient management during hospitalisation. TF advised the treatment and elaborated of this case report. AT contributed to endovascular treatment. KN is the key physician responsible for treatment.

\section{Funding}

None.

\section{Availability of data and materials}

The data that support the findings of this report are available from the Toyohashi Municipal Hospital. The author can make it available upon reasonable request.

\section{Declarations}

Ethics approval and consent to participate

Not applicable.

\section{Consent for publication}

The patient provided informed consent.

\section{Competing interests}

The authors declare that they have no conflicts of interest in association with this study.

\section{Author details}

'Department of Thoracic Surgery, Toyohashi Municipal Hospital, 50 Hachiken-nishi, Aotake-cho, Toyohashi, Aichi 441-8570, Japan. ²Department of Thoracic Surgery, Nagoya University, Nagoya, Japan. ${ }^{3}$ Department of Radiology, Toyohashi Municipal Hospital, Toyohashi, Aichi, Japan.

Received: 17 September 2020 Accepted: 22 April 2021

Published online: 30 April 2021

\section{References}

1. Davide $P$, Nikolaos $P$, Jonathan $P$, Gvinianidze L, labal $Y$, Lawrence DR. Etiology and management of spontaneous haemothorax. J Thorac Dis. 2015;7:520-6.

2. Clare ML, Francis W, John S. Massive hemothorax due to enlarging arteriovenous fistula in pregnancy. Chest. 1992;101:1452-4.

3. Pantazopoulos I, Papazoglow G, Strataki K, Chalkias A. Spontaneous hemothorax complicating von Recklinghausen disease: case report and treatment algorithm. J Emerg Med. 2019:58:e63-6.

4. Miura T, Kawano Y, Chujo M, Miyawaki M, Mori H, Kawahara K. Spontaneous hemothorax in patients with von recklinghausen's disease. Jpn J Thorac Cardiovasc Surg. 2010;10:128-30.

5. Brady DB, Bolan JC. Neurofibromatosis and spontaneous hemothorax in pregnancy: two case reports. Obstet Gynecol. 1984:63:35-8.

6. Sathianurthy N, Govindasamy HD, Seevalingam KK, Paramasvaran G, Ramasamy U. Spontaneous massive haemothorax in the peri-partum period of an undiagnosed neurofibromatosis type 1 patient - a surgical perspective. Med J Malaysia. 2019:74:99-101.

7. Brasfield RD, Gupta TKD. Von recklinghausen's disease: a clinicopathological study. Ann Surg. 1972;175(1):86-104. https://doi.org/10.1097/00000658-1972 01000-00015.
8. Greene JF Jr, Fitzwater JE, Burgess J. Arterial lesions associated with neurofibromatosis. Am J Clin Pathol. 1974;62(4):481-7. https://doi.org/10.1 093/ajcp/62.4.481.

9. Greaves I, Porter KM, Ryan JM. Trauma in women. In: Trauma care manual. London: Arnold; 2001. p. 191-204.

\section{Publisher's Note}

Springer Nature remains neutral with regard to jurisdictional claims in published maps and institutional affiliations.
Ready to submit your research? Choose BMC and benefit from:

- fast, convenient online submission

- thorough peer review by experienced researchers in your field

- rapid publication on acceptance

- support for research data, including large and complex data types

- gold Open Access which fosters wider collaboration and increased citations

- maximum visibility for your research: over $100 \mathrm{M}$ website views per year

At BMC, research is always in progress.

Learn more biomedcentral.com/submission 